\title{
Aeolian sand bearing capacity in the Mu Us Desert of China based on the California Bearing Ratio
}

\author{
Han XIA*, Jingtao ZHANG**,***, Guangyin DU*, Huangsong PAN*, Wei DUAN* and Xuesen SHE*** \\ *Institute of Geotechnical Engineering, Southeast University, Nanjing 211189, China \\ **China Communications Construction Company First Highway Consultants Company Limited, Xi'an 710075, China \\ ***School of Highways, Chang'an University, Xi'an 710061, China \\ *Corresponding Author: guangyin@seu.edu.cn
}

\begin{abstract}
Aeolian sand is widely distributed worldwide from the Middle East to sub-Saharan Africa, from Central Australia to Western America: it can be seen everywhere. The California bearing ratio (CBR) is one of the most commonly used methods of evaluating the strength of a sub-grade soil, sub-base, or base course material both for designing and determining the thickness of highways and airfield pavements and for measuring the load-bearing capacity of soils used in building roads. This paper aims to test different moisture contents, mud contents, and gradations that affect aeolian sand strength and bearing capacity using the CBR method. Using sand samples collected in the Mu Us Desert in the northwest of China, a series of laboratory tests have been carried out to test the influence of moisture content, mud content, and dry density on the soil. The optimum moisture content of aeolian sand in the Mu Us Desert is approximately $10-12 \%$. CBR increases with increasing moisture content before Optimum Moisture Content and decreases with increasing moisture content after Optimum Moisture Content. The Optimum Mud Content of aeolian sand is $10-40 \%$; before optimum mud content, CBR increases with increasing mud content; after optimum mud content, CBR decreases with increasing mud content. CBR increases with increasing dry density of aeolian sand; CBR decreases with decreasing dry density of aeolian sand. With fixed coarse particle content, CBR increases with increasing fine particle content of aeolian sand before optimal mud content; CBR decreases with increasing medium particle content of aeolian sand after optimal mud content. When the moisture content reached OMC, it was easier to compact aeolian sand, the density of sand reached maximum dry density, and the particles were more difficult to move; therefore, shear strength reaches the maximum and CBR reaches the maximum accordingly.
\end{abstract}

Keywords: Aeolian sand, California Bearing Ratio (CBR), moisture content, mud content, gradation.

\section{INTRODUCTION}

Aeolian sand particles are composed of weathered rock, and they are widely distributed in Northwest China, across Qinghai, Ningxia, Shaanxi, and Inner Mongolia. The depth of the soil ranges from several meters to one hundred meters (Milton, D. I., 1967; Watson, A., 1985; Wu, Z., 2003). Aeolian processes, also spelled eolian or æolian, pertain to wind activity in the study of geology and weather and specifically to the ability of wind to shape the surface of the Earth (Fig.1 (a) \& (b)). Different sedimentary histories and conditions give the sand different characteristics. In recent years, China has provided a series of major cooperation initiatives such as the Silk Road Economic Belt and the 21st Century Maritime Silk Road, or "One Belt and One Road" for short (Du, J. et al., 2018). Many countries in the Silk Road Economic Belt have large areas of aeolian sand desert; to develop and increase communication among those countries, an increasing number of expressways, railways, and other buildings are being built in aeolian sand desert areas.

To investigate the influence of moisture content and sand content on aeolian sand, a series of tests were undertaken in the Mu Us Desert of China. We tested the water content, mud content, and compaction work and learned how the change in aeolian sand reveals the influence of the California bearing ratio (CBR) changes. 


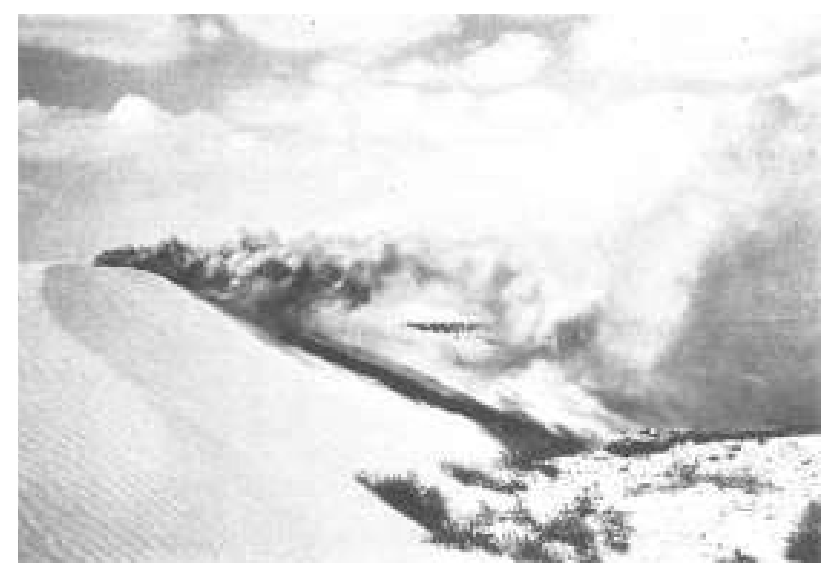

(a) Aeolian processes

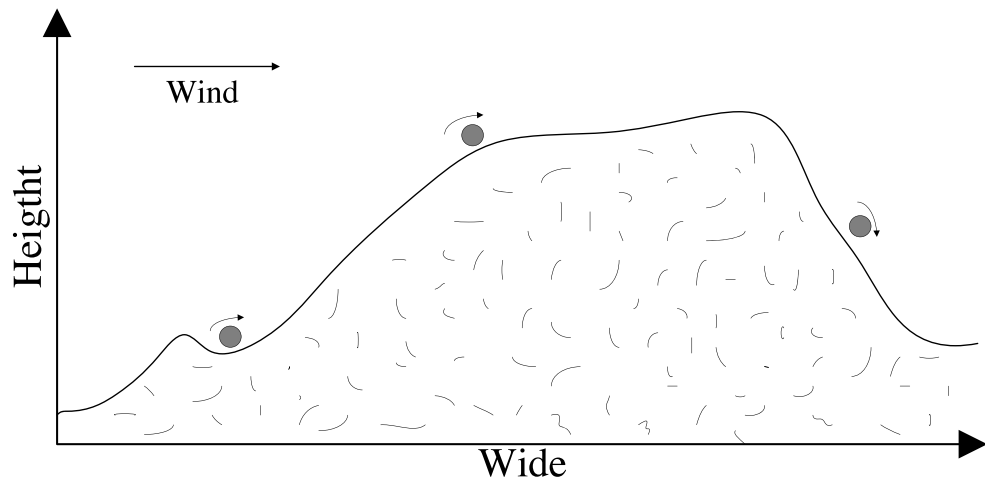

(b) Aeolian processes explanation

Figure 1. Aeolian processes (Pye, K. \& Tsoar, H., 2009).

\section{Literature Review}

Aeolian sand is a special type of soil that has characteristics different from those of clay and silt, such as sensitivity to water, large pore size, high structure, and a high void ratio. This soil has a loose structure, macropores, particles of homogeneous size, and poor self-stabilization and is easily caught up to pollute the environment (Li, D., 2018). The continuous deposition of sands results in the formation of sand dunes, which have unique characteristics that change their location, length, and height depending on the direction and intensity of the wind (Tsoar, H., 2001). Such soil also has a good character in that it is difficult to compact for construction. In the 1970s and 1980s, many researchers (Knott, 1979; Lee, J. A., 1987) used micrometeorological information to study small sand dunes. With the development of numerical simulation, researchers increasingly used the numerical modelling technique in aeolian sand studies (Walmsley, J. L., et al., 1985; Fisher, P. F., et al., 1988). Shao (Shao, Y. P., et al., 1996) describes a Wind Erosion Assessment Model to estimate sand drift and dust entrainment in agricultural areas. Andreotti (Andreotti, B. A., 2004) uses two models to study aeolian sand transport.

Currently, an increasing amount of critical infrastructure such as expressway and high-speed railways is under construction on aeolian sand. Those projects pay more attention to aeolian sand strength and bearing capacity, and it is necessary to study the properties of treatment methods for aeolian sand. Sun (Sun, J., et al., 1996) and Liu (Liu, Z., et al., 2008) reported on the geological origin of this desert, and Yang (Yang, Y., et al., 2006) noted that population migration has affected this area since the Tang dynasty. Song (Song, Y., et al., 2010) showed that aeolian sand in the $\mathrm{Mu}$ Us Desert is different from silt and mud soil. Many studies have described the climate and environmental evolution of the Mu Us Desert (Liu, Z., et al., 2008; Niu, D., et al., 2015; Ma, J., et al., 2011). Other scholars have also 
illustrated aeolian sand's mineralogical and geomorphological characteristics (Ahlbrandt, T. S., 1979; Pease, P., et al., 1999, Howari, F. M., et al, 2007). Zhenghu (Zhenghu, D., et al., 2007) performed research on the morphological and physicochemical properties of aeolian sand. Al-Sanad et al. (Al-Sanad, H. A., 1993) performed a series of laboratory tests on sand from dunes in Kuwait. Studies have also been conducted to stabilize dune sand in Kuwait on the Arabian Peninsula (Philips, C. J., et al., 1978; Al-Sanad, H. A., et al., 1984).

\section{THE GEOLOGY OF THE MU US DESERT OF CHINA}

The $\mathrm{Mu}$ Us Desert is located in Erdos and Yulin between $37^{\circ} 27^{\prime}-39^{\circ} 22^{\prime} \mathrm{N}$ and $107^{\circ} 20^{\prime}-111^{\circ} 30^{\prime} \mathrm{E}$, between South Inner Mongolia and North Shaanxi province, and is 40,000 square kilometers, as depicted in Fig. 2. This area lies within China's western monsoon region, has the characteristics of a temperate zone with a continental monsoon climate, and is a transition zone from desert to steppe to forest steppe (Yang, Y., et al., 2006). In this region, the annual average temperature is between 6.0 and $8.5^{\circ} \mathrm{C}$, and the maximum and minimum temperatures during winter range from -9.5 to $-12{ }^{\circ} \mathrm{C}$. The maximum and minimum temperatures during summer range from 25 to $42{ }^{\circ} \mathrm{C}$, and the annual accumulated temperature is approximately $3000{ }^{\circ} \mathrm{C}$. Annual precipitation is $260-450 \mathrm{~mm}$, and evaporation is 1800 - $2500 \mathrm{~mm}$; sunshine duration is greater than $2700 \mathrm{~h}$, and every year, there is more than $5 \mathrm{~m} / \mathrm{s}$ of blowing sand from 220 to 580 times on average.

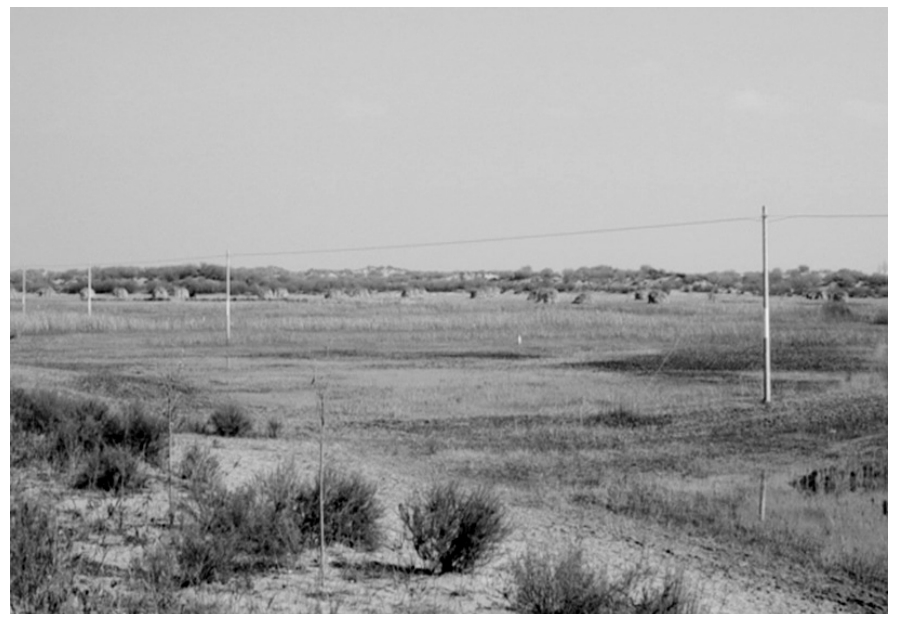

Figure 2. Mu Us Desert in Yulin, Shaanxi Province, China.

In this area, the ground elevation is at 1100 1300 meters, and the terrain is relatively flat; all kinds of sand dunes may be found scattered across the desert, along with some billabongs and small lakes between sand dunes. The large sand dunes are approximately $10-20 \mathrm{~m}$, and the smaller sand dunes are approximately $5 \mathrm{~m}$. The landform types are fixed and semi-fixed dunes, valley terraces, and lake basins. This region belongs to the eastern part of the northern margin of the Ordos Basin, where the crust is relatively stable, the geological structure is simple, the active faults in the region are not developed, and seismic activity is weak. In this region, the soil can be divided into four layers: silty sand, fine sand, medium sand, and coarse sand. The silty sand layer contains a small amount of organic matter and 10 - 50\% sand. Fine sand is brownish yellow, saturated, and contains feldspar, quartz and other minerals (Fig. 3). The yellow medium sand with high moisture content and low density is inhomogeneous. 


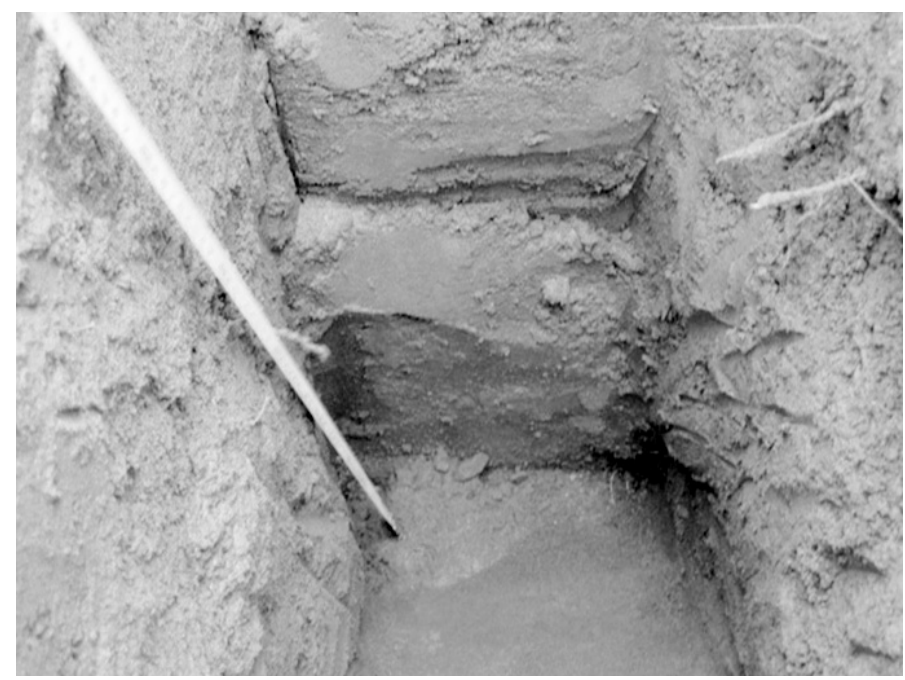

Figure 3. Sand in the Mu Us Desert.

\section{CALIFORNIA BEARING RATIO}

\section{Theory}

The CBR is one of the most commonly used methods to evaluate the strength of a subgrade soil, subbase, or base course material to design and determine the thickness for highways and airfield pavements and to measure the loadbearing capacity of the soils used in building roads.

The CBR can be calculated according to the following equation (ASTMD1883-78):

$$
C B R=\frac{p}{p_{s}} \cdot 100
$$

where $C B R$ is the California bearing ratio (\%), $p$ is the measured pressure of soils $\left(\mathrm{N} / \mathrm{mm}^{2}\right)$ and $p_{\mathrm{s}}$ is the pressure to achieve equal penetration on standard soil $\left(\mathrm{N} / \mathrm{mm}^{2}\right)$.

At $2.5 \mathrm{~mm}$ depth of penetration, the following equation is used (JTG E40-2007):

$$
C B R=\frac{p}{7.0} \times 100 \%
$$

where $p$ is the measured pressure for soils $\left(\mathrm{N} / \mathrm{mm}^{2}\right)$.

At $5 \mathrm{~mm}$ depth of penetration, the following equation is used (JTG E40-2007):

$$
C B R=\frac{p}{10.5} \times 100 \%
$$

If the CBR at $5 \mathrm{~mm}$ is greater than at $2.5 \mathrm{~mm}$, this test must be repeated; if the result remains the same, the value at $5 \mathrm{~mm}$ is used.

\section{Testing equipment and procedure}

The electric pavement material strength tester requires that the penetration energy is no less than $50 \mathrm{kN}$, and the penetration rod is $50 \mathrm{~mm}$ in diameter with a length of approximately $100 \mathrm{~mm}$. At the top of the soil specimen (diameter $15.24 \mathrm{~cm}$ and $11.43 \mathrm{~cm}$ length), a rigid indenter (diameter $4.95 \mathrm{~cm}$ ) is used with a deformation rate of $1.27 \mathrm{~mm}$ per 
minute. Mud content, moisture content, and particle gradation are different at every place in the desert. This paper tests the three factors of moisture content, mud content, and gradation and determines how they affect the strength and bearing capacity of aeolian sand. The CBR testing equipment is shown in Figure 4.
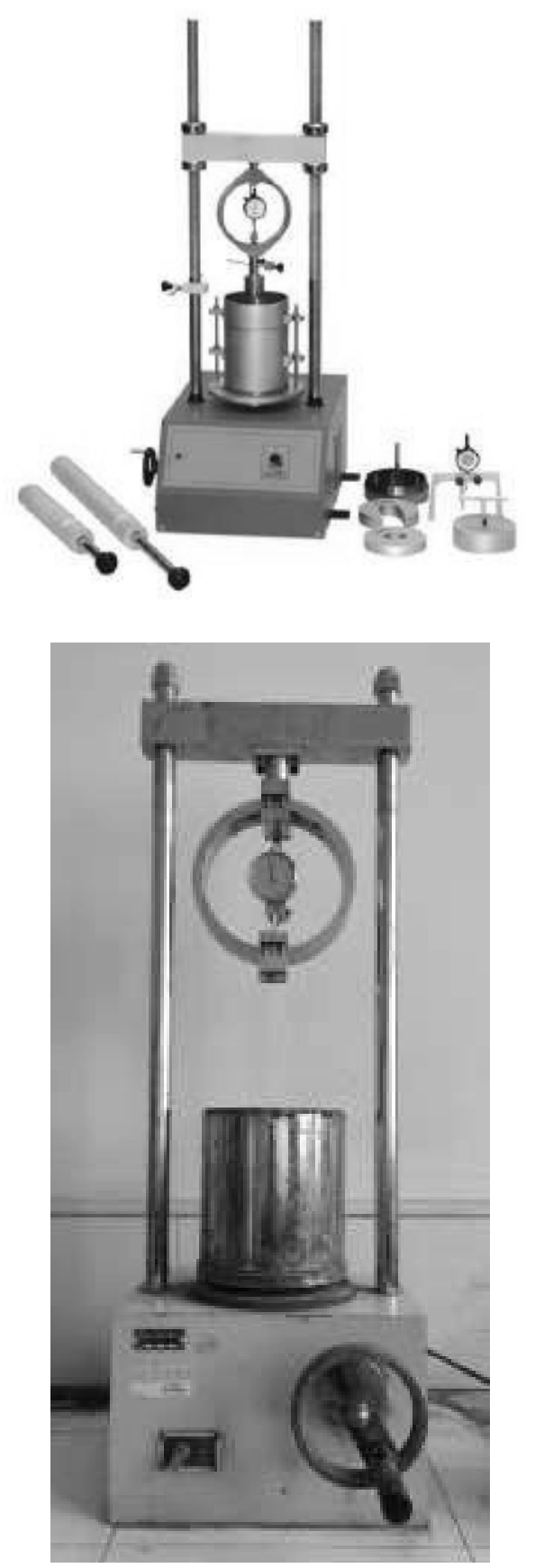

Figure 4. CBR testing equipment. 


\section{RESULT AND DISCUSSION \\ The effect of different moisture contents}

Moisture content has a great influence on aeolian sand strength because aeolian sand is unsaturated soil, and water can provide the matrix suction to reinforce shear strength. To test the influence of different moisture content for CBR, five places in Mu Us Desert are sampled, and the values of the moisture content of each sample are $6 \%, 8 \%, 10 \%$, $12 \%$, and $14 \%$ to test their CBR values; the results can be seen in Fig. 5.

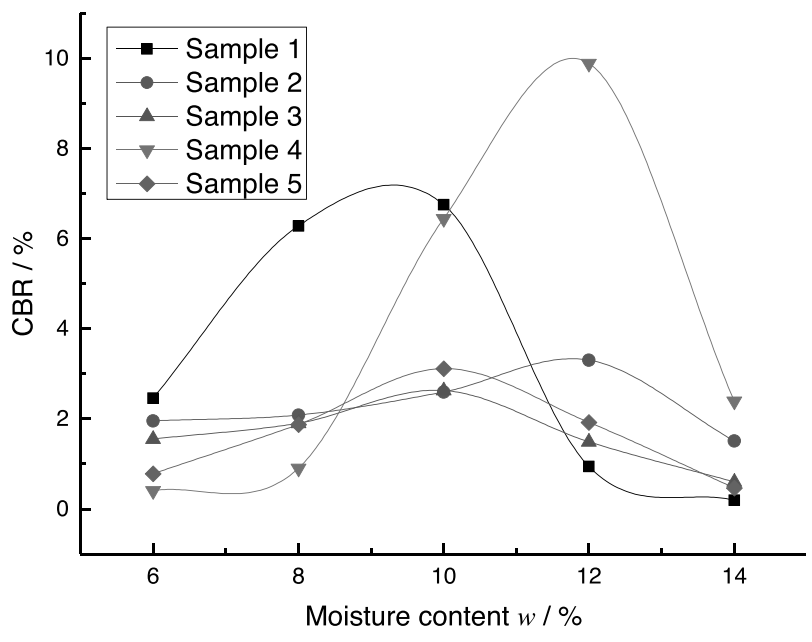

Figure 5. CBRs for different moisture contents.

As shown in Figure 4, moisture content significantly affects CBR. Different samples from the Mu Us Desert have different values of CBR. Sample 1 curve reaches its peak sooner and at a lower moisture content than the curves for the other four samples; Sample 2 and Sample 4 reach their peaks at higher moisture contents. This result might occur because mud content will affect the soil's optimal moisture.

In the low moisture content state (below the optimum moisture content), aeolian sand is in a dry and loose state, and the gravitational force between particles causes the soil to maintain a relatively loose state and condensed structure. At this time, the pores in the soil are mutually connected and filled with water and gas. Density can be increased under the action of an external compaction force; this effect occurs because the gas in the pores can be easily ejected, and the water film mostly cannot play a role in lubrication; thus, the compaction effect is not good. Increasing the moisture content, the water film becomes thicker, the soil becomes softer, and the gravitational force decreases. Increasing the external compaction force can mutually dislocate the soil particles and increase the density, so the CBR value increases. At the optimum moisture content, the soil density reaches a peak value under the compaction work, and soil particles are close together because of bound water and matrix suction absorbance, so the CBR reaches a peak. When the moisture content is greater than the optimum moisture content, free water appears in the pores, and it is impossible to discharge the soil gas by striking; thus, pore pressure significantly increases. Pore pressure counteracts the partial compaction work and the compaction effect and density also decrease, so the CBR value decreases correspondingly.

\section{The effect of different mud contents}

Aeolian sand is composed of sand and small amounts of silt and clay. To analyze the effect of clay particles on the CBR, soil samples with the same moisture content and different mud contents were taken. Sample 1 takes the mud content as 5\%, 10\%, 20\%, 30\%, 40\%, 50\%, and 60\%; Sample 2 takes the mud content as $20 \%, 40 \%, 50 \%, 60 \%, 70 \%$, and $80 \%$; and for both Sample 1 and Sample 2, the moisture content is $12 \%$. 


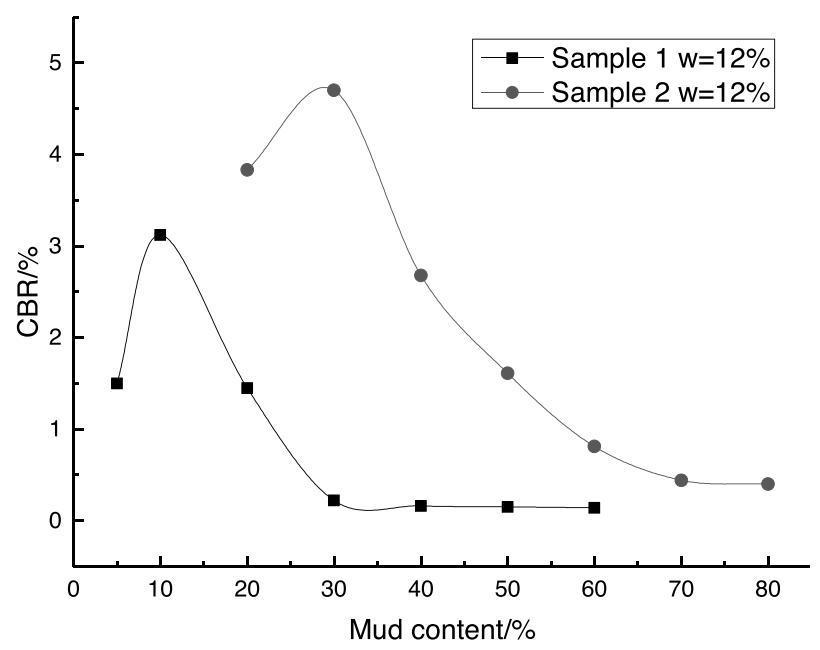

Figure 6. CBRs for different mud contents.

Fig. 6 illustrates that the content of mud particles is the other main factor affecting the strength of aeolian sand. Given the same moisture content, the CBR value increases with increasing mud content. When mud content is below the optimal value, the CBR is lower. When mud content is optimal, the CBR reaches its maximum value. When mud content exceeds optimal value, the CBR begins to decrease.

The reason for this relation is that, with less mud, aeolian sand is simpler; the particle size change is not obvious and the particles are mainly in contact. When the pores in the soil are large, the main bonding force between the particles is water tension, so the ability to resist external damage forces is poor, and the CBR is relatively low. When mud content reaches its optimal value, which indicates aeolian sand with a good grain size, resistance force increases, and the CBR value is relatively high. When mud content exceeds the optimal value, a further increase in mud content turns the soil into fine sand; because there are many clay minerals, the performance of silt or clay characteristics overwhelms that of sand. Once the moisture content increases, the soil particles absorb the water, the overall soil softens, and the shear strength weakens, so the CBR value also decreases.

\section{The effect of different compaction work under optimal moisture content}

Sampling is performed in four places in the Mu Us Desert to test the compaction times with CBRs of 30, 50, and 98. The four samples have different dry density (Tab. 1), and the results of four samples with different compaction work are shown in Fig. 7.

Table 1. Dry density of four samples.

\begin{tabular}{|c|c|c|c|c|}
\hline Number & $\mathbf{1}$ & $\mathbf{2}$ & $\mathbf{3}$ & $\mathbf{4}$ \\
\hline Dry density $/ \rho_{\mathrm{d}} / \mathrm{g} / \mathrm{cm}^{3}$ & 1.942 & 1.832 & 1.696 & 1.557 \\
\hline
\end{tabular}




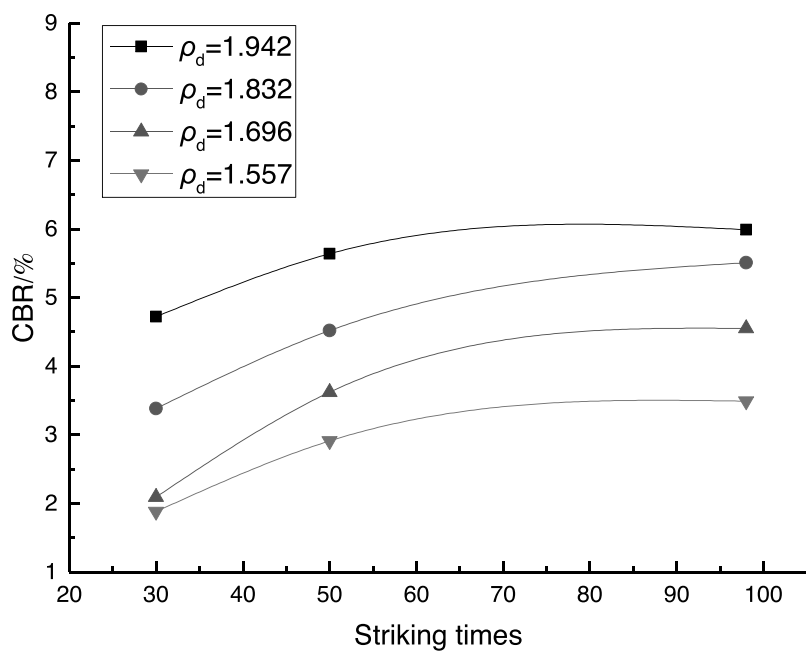

Figure 7. CBRs under different compaction work.

The CBR values for different soil types are different under the same compaction work. Sample 1 has a high dry density, and the CBR curve is higher than that of the other samples. Sample 4 has the lowest dry density of the all samples, so the value is lowest. In other words, when dry density increases, the CBR value increases. This result occurs because the soil sample with high dry density has coarse grains, and the particles do not easily move relatively to each other under the external force.

With the increase in compaction work, the CBR value also increased. This effect occurs because the compaction work to reduce the volume of soil voids and pores decreases, leading to an increase in the effective contact area of soil particles, an increase in the dry density, and an increase in the ultimate shear strength of the soil. For the same soil, with increasing compaction work, the optimal moisture content decreases gradually; the dry density also increases, and the CBR value increases.

\section{The effect of different gradation}

Different gradations may affect the soil shear strength, and different mud content also affects strength. The gradation is set with $70 \%$ coarse particles $(2 \mathrm{~mm}>\mathrm{C} \geq 0.5 \mathrm{~mm}) ; 10 \%, 15 \%$, and $20 \%$ medium particles $(0.5 \mathrm{~mm}>\mathrm{M}$ $\geq 0.25 \mathrm{~mm})$; and $20 \%, 15 \%$, and $10 \%$ fine particles $(\mathrm{F}<0.25 \mathrm{~mm})$ with mud content $(\leq 0.05 \mathrm{~mm})$ of $20 \%, 40 \%, 60 \%$, and $80 \%$, and control moisture content kept at $14 \%$. The results are shown in Fig. 8.

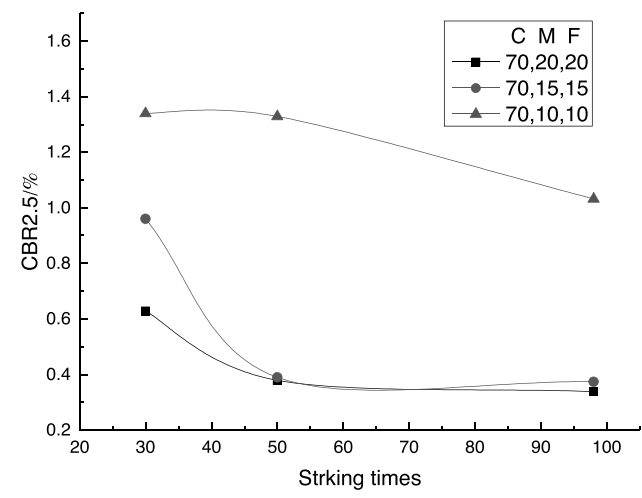

(a) $\mathrm{CBR}=2.5$ with $80 \%$ mud content

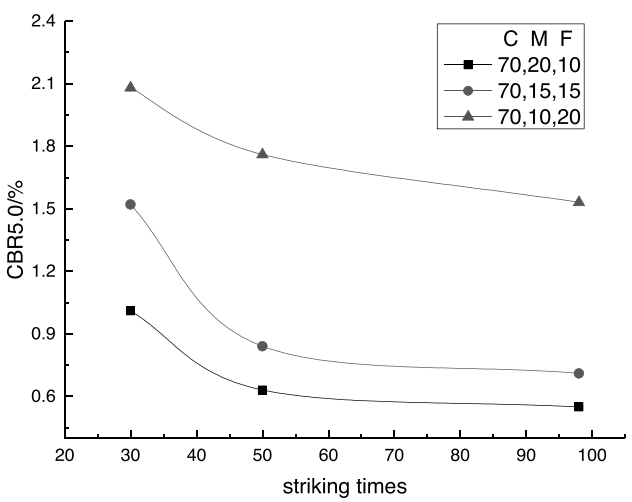

(b) $\mathrm{CBR}=5.0$ with $80 \%$ mud content 


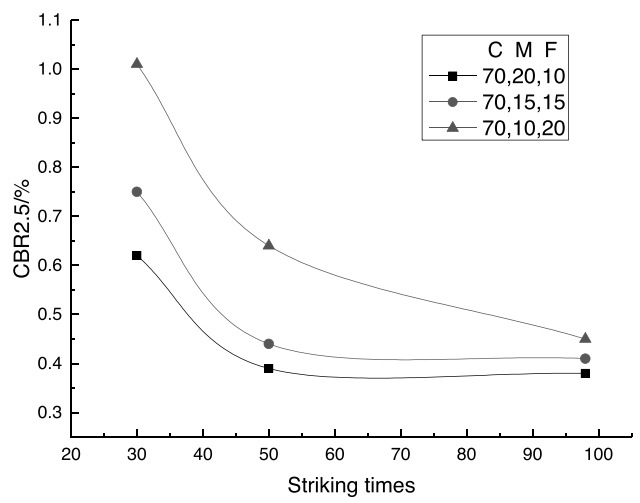

(c) $\mathrm{CBR}=2.5$ with $60 \%$ mud content

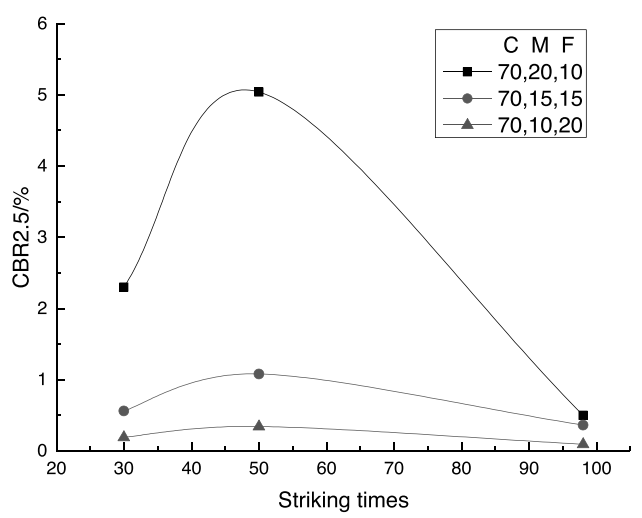

(e) $\mathrm{CBR}=2.5$ with $40 \%$ mud content

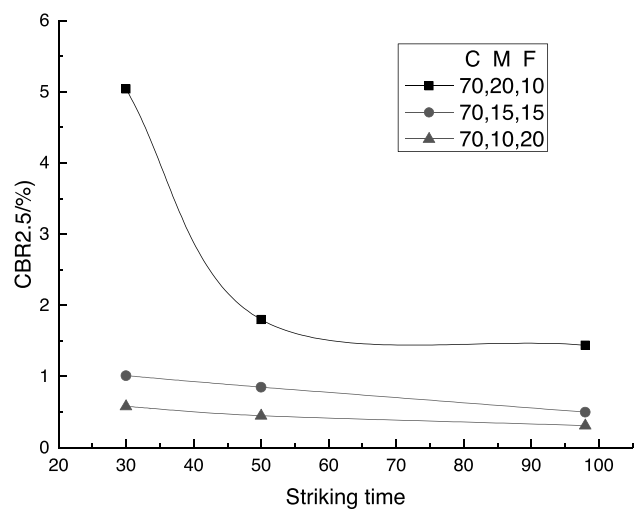

(g) $\mathrm{CBR}=2.5$ with $20 \%$ mud content

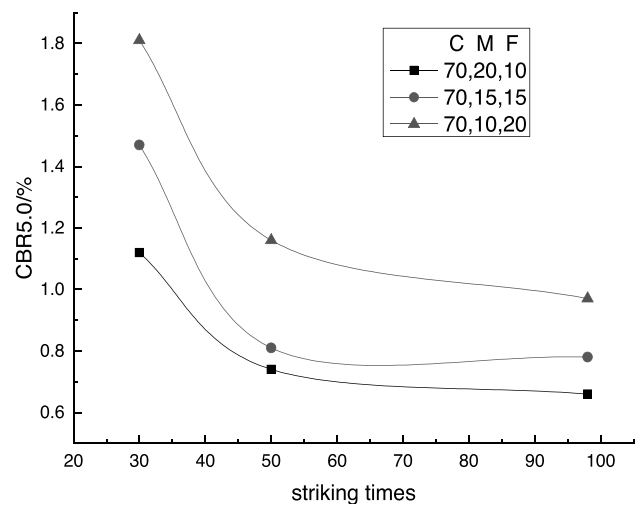

(d) $\mathrm{CBR}=5.0$ with $60 \%$ mud content

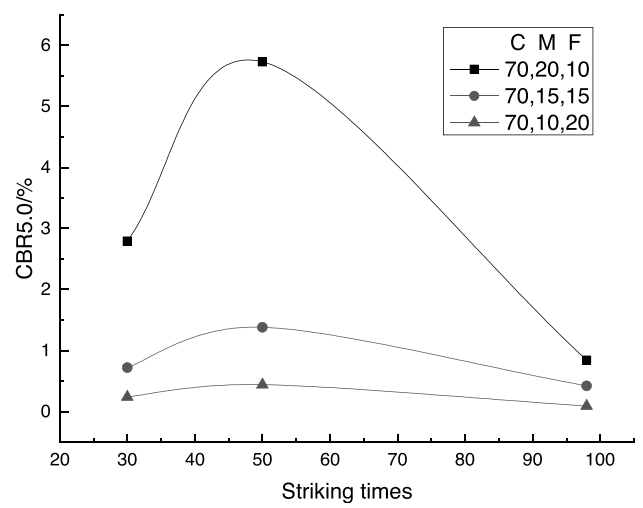

(f) $\mathrm{CBR}=5.0$ with $40 \%$ mud content

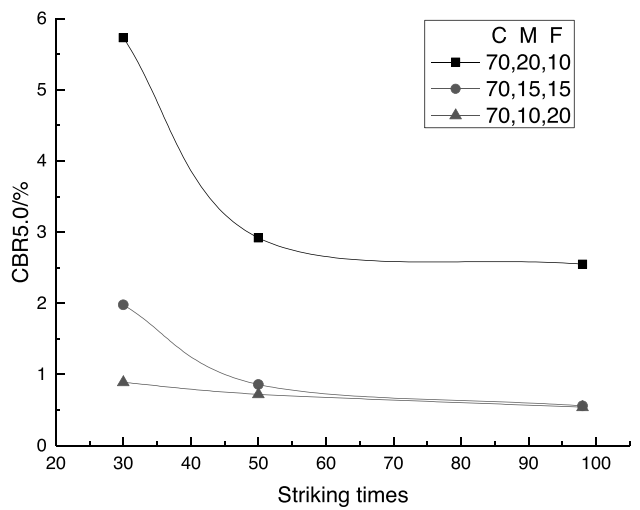

(h) $\mathrm{CBR}=5.0$ with $20 \%$ mud content

Figure 8. The relationship between mud content and CBR.

The graphs show that the particle size of sand also affects the CBR value. As the mud content and compaction work in aeolian sand increases, the CBR value decreases. In the $60 \%$ and $80 \%$ mud content samples (Figure 8 (a) (d)), the CBRs decrease with striking times increases; in the $40 \%$ mud content samples (Figure 8 (e) and (f)), CBRs first increase and then decrease after reaching maximum value at the 50 striking time; in the $20 \%$ mud content sample (Figure $8(\mathrm{~g})$ - (h)), the CBR also decreases when striking times increase. In other words, the $40 \%$ mud content at 50 striking times is the optimum mud content. 
In the $20 \%$ and $40 \%$ mud content samples, the CBRs increase when medium particle contents increase; in the $60 \%$ and $80 \%$ mud content samples, the CBRs decrease when the medium particle contents increase. The results mean that mud content increase in fine particles influenced the CBR efficiently. In the $60 \%$ and $80 \%$ mud content samples, small particles can easily fill the pores of soil, and the soil density becomes high. In the $40 \%$ and $20 \%$ mud content samples, there are too few small particles to fill the pores of sand, and the soil density is accordingly low. Field density, dry density, bulk density, and cohesion of soil are directly proportional to the CBR. This is because as the density of soil increases, the soil particles become more compact so that they can carry more loads or stresses. Therefore, as CBR increases, the strength of sand increases.

\section{The effect of different moisture and mud contents}

The results can be seen in Fig. 9 (a) \& (b). For the different moisture contents $(6 \%, 8 \%, 10 \%, 12 \%$, and 14\%.), the value of the CBR increases with compaction work at first and finally decreased in high moisture content (10\%, 14\%); these results are in agreement with Yashas, S. R. (Yashas, S. R., et al., 2016), seen in Fig. 10. In the moisture content $14 \%$ sample, the maximum CBR value in the sample is 60 striking times, in the moisture content $10 \%$ sample, the maximum CBR value in the sample nearly 70 striking times, and the CBR value of others has reached 98 times. This phenomenon may be because the moisture content of the soil is too high to cause the soil to become saturated, which results in the decrease of soil strength.

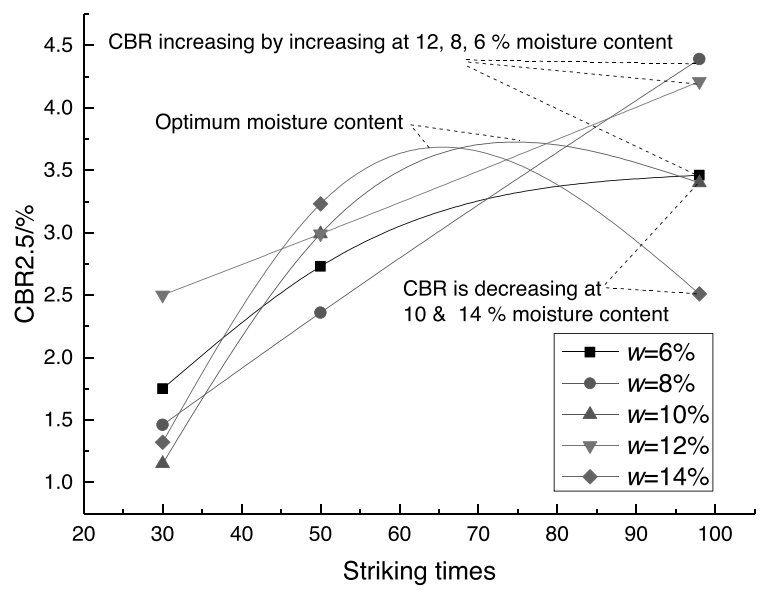

(a) $\mathrm{CBR}=2.5$ in different moisture content

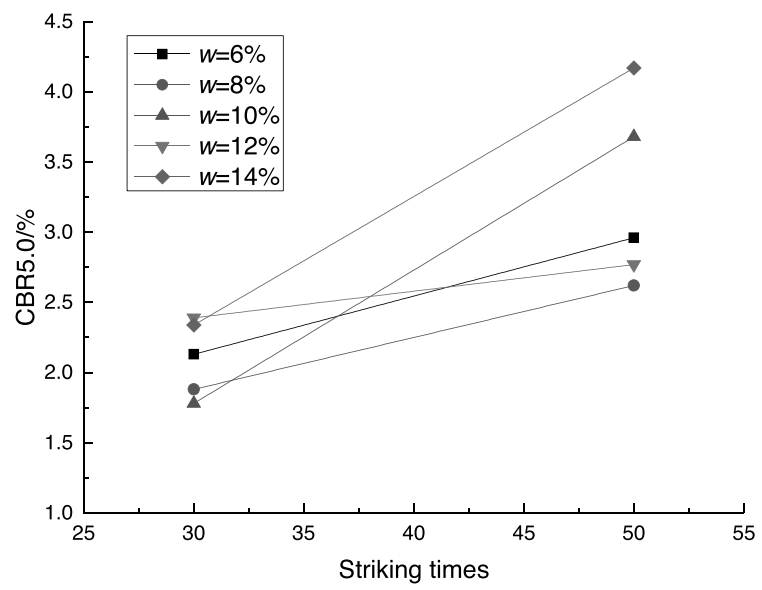

(b) $\mathrm{CBR}=5.0$ in different moisture content

Figure 9. CBR in different moisture content. 


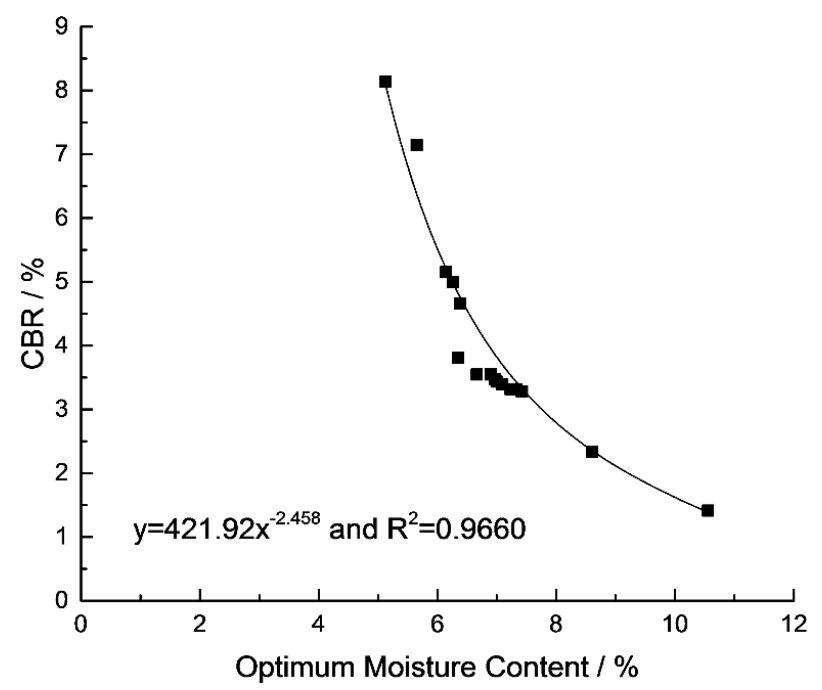

Figure 10. Graph plotted for OMC versus CBR (Yashas, S. R. et, al., 2016).

Given the same compaction conditions, striking 50 and 30 times, the CBR value of the sample increases with the increasing moisture content; when each sample is compacted 98 times, the basic trend in the CBR value change first increases and then decreases. Aeolian sand is a typical unsaturated soil; when the moisture content reaches Optimum Moisture Content (OMC), water in the soil can contact the soil particle and form water film, which can provide matric suction. Therefore, the friction between particles reached its maximum and its strength was maximized accordingly.

\section{CONCLUSIONS}

Aeolian sand is a common soil widely distributed around the world. However, it has different engineering properties from other foundation soils. This paper focuses on the bearing capacity of aeolian sand through an effective test method - the California Bearing Ratio (CBR). The soil samples are collected from 5 different places in the Mu Us Desert, and soil samples in each place can be divided into 5 kinds of moisture content $(6 \%, 8 \%, 10 \%, 12 \%$, and $14 \%)$ to test each of the 25 samples' CBR. Thus, the moisture content is controlled at $12 \%$, and the mud content is changed to test the influence of mud particle content on CBR. Next, we control the 4 dry densities from the same sample to test dry density's influence on the CBR. Finally, we set coarse particle: medium particle: fine particle content as (70:10:20), (70:15:15), and (70:20:10) to test the different gradation influence on CBR. The results can be summarized as follows:

(1) For the samples collected in each place of the Mu Us Desert, each sample has Optimum Moisture Content (OMC). The OMC of aeolian sand in Mu Us Desert is approximately $10-12 \%$. Below OMC, the CBR increases with the increase in moisture content; above OMC, the CBR decreases with increasing moisture content.

(2) Aeolian sand in the Mu Us Desert also has an optimum mud content from $10 \%$ to $40 \%$. Below optimum mud content, the CBR increases with increasing mud content. Above optimum mud content, the CBR decreases with mud content increasing.

(3) The CBR increases with the increasing dry density of aeolian sand; the CBR decreases with the decreasing dry density of aeolian sand.

(4) For the fixed coarse particle content, the CBR increases with the medium particle content of aeolian sand increasingly blowing with optimal mud content; the CBR decreases with the medium particle content of aeolian sand increasing above optimal mud content. 
(5) The sand reaches $\mathrm{OMC}$ and optimum mud content, indicating that the density of sand reached its maximum dry density. Then, it becomes more difficult for the particles to move; at this time, aeolian sand was more easily compacted. Therefore, shear strength reaches the maximum, and the CBR reaches its maximum value.

(6) For the sand above OMC and optimum mud content, aeolian sand particles are easily moved to enlarge the pores, and therefore, shear strength and CBR decrease.

\section{REFERENCES}

Ahlbrandt, T.S. 1979. Textural parameters of aeolian deposits. In: McKee, E.D. (Ed.), A Study of Global Sand Seas United States Geological Survey Professional Paper, 1052: 23-32.

Al-Sanad, H.A., Ismael, N.F. \& Nayfeh, A.J. 1993. Geotechnical properties of dune sands in Kuwait. Engineering Geology, 34(1-2):45-52.

Al-Sanad, H.A. \& Bindra, S.P. 1984. Soil mechanics for road engineers in Arabian Peninsula. Jami at al-Kuwayt, Kuwait.

Andreotti, B.A. 2004. Two-species model of aeolian sand transport. Journal of Fluid Mechanics, 510(10):47-70.

ASTM D1883-78. 2016. Standard test method for California Bearing Ratio (CBR) of laboratory-compacted soils. American Society for Testing Materials.

Du, J. \& Zhang, Y. 2018. Does one belt one road initiative promote Chinese overseas direct investment?. China Economic Review, 47(2):189-205.

Fisher, P.F. \& Galdies, P.A. 1988. Computer model for Barchan-Dune movement. Computers \& Geosciences, 14(2):229-253.

Howari, F.M., Baghdady, A. \& Goodell, P.C. 2007. Mineralogical and geomorphological characterization of sand dunes in the eastern part of United Arab Emirates using orbital remote sensing integrated with field investigations. Geomorphology. 83(1): 67-81.

JTG E40-2007. 2007. Test method of soils for highway engineering. Ministry of Transport of the People's Republic of China.

Knott. 1979. The structure and pattern of dune-forming winds. Glia, 61(2):129-139.

Lee, J. A.. 2010. A field experiment on the role of small scale wind gustiness in aeolian sand transport. Earth Surface Processes \& Landforms, 12 (3):331-335.

Liu, Z., Wang, H. \& He, S. 2008. Ecological economics model and ensure system of Mu Us Desert based on the cause of formation and present situation. Ecological Environment. 10(1):136-139.

Lu, R., Xia H., Qiang, M. \& Zhang, D. 2008. Environmental evolution in past 130 years recorded by Bojianghaizi lake sediments in north Mu Us Desert, China. Journal of Desert Research, 28(1):44-49.

Ma, J., Yue, L., Yang L., Sun, L. \& Xu, Y. 2011. OSL dating of holocene sequence and palaeoclimate change record in southeastern margin of Mu Us Desert, north China. Quaternary Science. 31(1):121-129.

Milton, D.I. 1963. Geology of the Arabian Peninsula: Kuwait. Geological survey professional paper. A review of the surface geology of Kuwait as shown on USGS Miscellaneous Geologic Investigations Map I-270 A. 560-F.

Niu, D., Li B., Wang, F., Chen, Q. \& Shu, P.X. 2015. Holocene climate fluctuations from the record of trace elements in the Mu Us Desert: evidence from the DGS1 segment of the Salawusu river valley. ACTA Sedimentologica Sinica. 33(4):735-746.

Pease, P., Bierly, G., Tchakerian, V. \& Tindale, N. 1999. Mineralogical characterization and transport pathways of dune sand using Landsat TM data, Wahiba Sand Sea, Sultanate of Oman. Geomorphology. 29(3-4):235-249.

Phillips, C.J. \& Willetts, B.B. 1978. A review of selected literature on sand stabilization. Coastal Engineering. 2:133-147.

Pye, K. \& Tsoar, H. 2009. Aeolian sand and sand dunes. Springer-Verlag Berlin Heidelberg.

Shao, Y.P., Raupach, M.R. \& Leys, J.F. 1996. A model for predicting aeolian sand drift and dust entrainment on scales from paddock to region. Australian Journal of Soil Research, 34(3):309-342.

Song, Y., Peng, J., Wang, Z., Li, X. \& Zhao, X. 2010. Test study on mechanical characteristic of aeolian sand in Mu Us Desert. Journal of Engineering Geology. 18(6):894-899. 
Sun, J., Liu, T., Ding Z. \& Liu J. 1996. The Mu Us Desert evolution in the last 0.5Ma. Quaternary Sciences, 11(4):360-367.

Tsoar, H. 2001. Types of aeolian sand dunes and their formation. Lecture Notes in Physics, 582:403-429.

Walmsley, J.L. \& Howard, A.D. 1985. Application of a boundary-layer model to flow over an aeolian dune. Journal of Geophysical Research Atmospheres, 90(D6):10631-10640.

Watson, A. 1985. The control of windblown sand and moving dunes: a review of the methods of sand control in deserts with observation from Saudi Arabia. Quarterly Journal of Engineering Geology \& Hydrogeology. 18(3): 237-252.

Wu, Z. 2003. Geomorphology of wind-drift sands and their controlled engineering. Science Press, Beijing.

Yang, Y., Yang, G., Feng, Y. \& Ren, G. 2006. Study on the process of desertification of Mu Us Desert. Journal of Northwest Agricultural and Forest University (Nature sciences). (34)8:103-108.

Yashas, S.R., Harish, S.N. \& Muralidhara, H.R. 2016. Effect of California Bearing Ratio on the properties of soil. American Journal of Engineering Research, 5(4):28-37.

Zhenghu, D., Honglang, X., Zhibao, D., Gang, W. \& Darke, S. 2007. Morphological, physical and chemical properties of aeolian sandy soils in northern China. Journal of Arid Environments. 68(1): 66-76.

Submitted: $11 / 05 / 2017$

Revised: $29 / 09 / 2018$

Accepted: $03 / 10 / 2018$ 


\title{
قياس قدرة تحمل الرمال الريحية في صحر اء مو أوس الصينية بواسطة اختبار نسبة تحميل كاليفورنيا
}

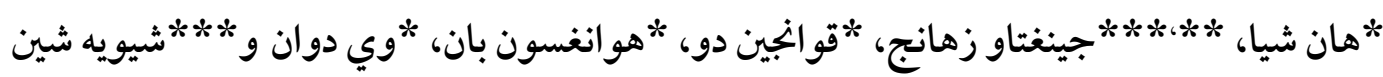

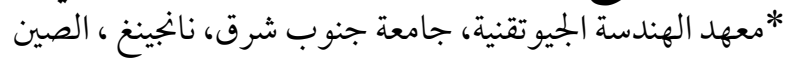

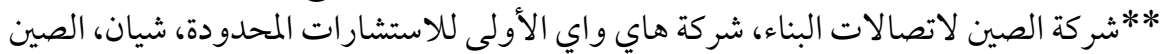

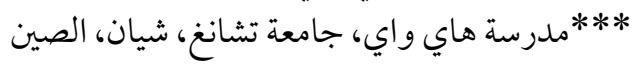

\section{الخالاصة}

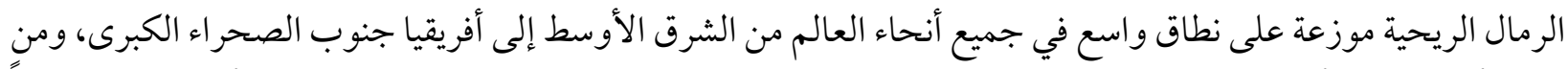

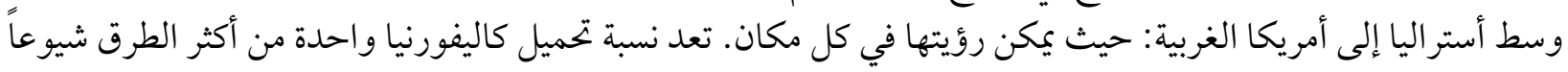

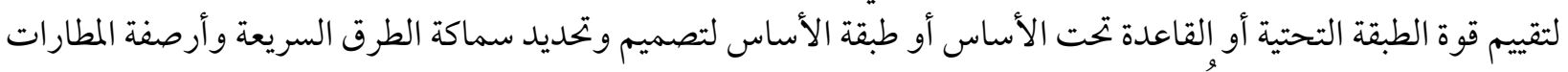

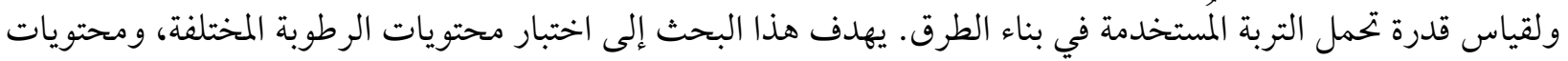

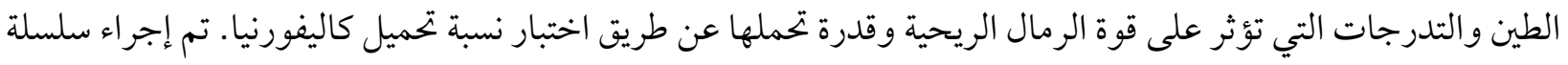

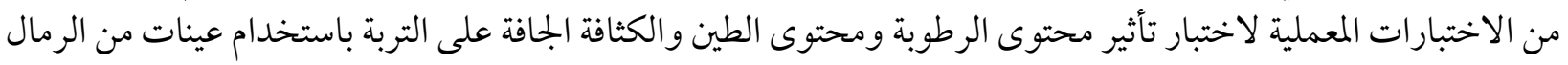

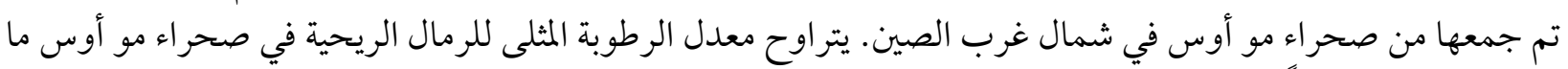

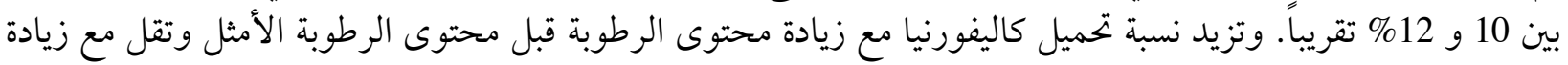

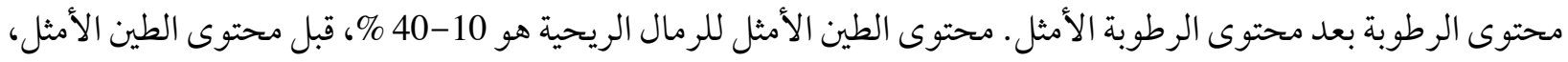

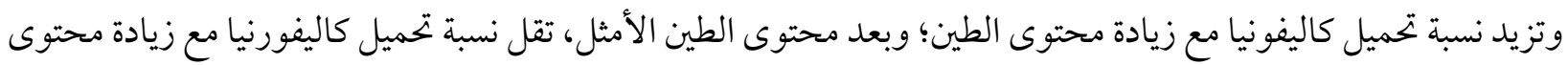

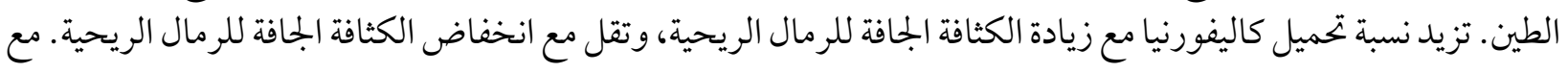

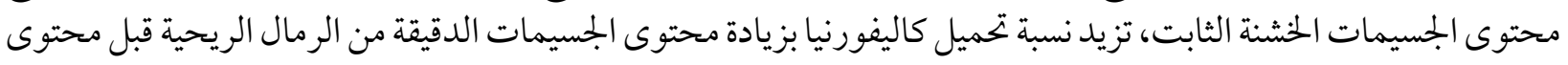

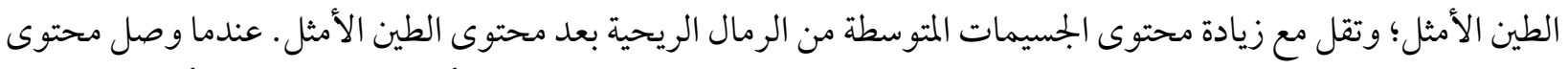

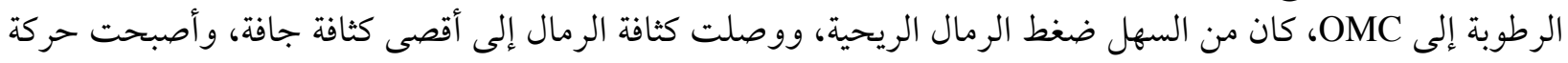
الجزيئات أكثر صعوبة، وبالتالي، تصل قوة القص إلى الحد الأقصى وبالتالي تصل نسبة تحميل كاليفورنيا إلى الحد الأقصى. 